\title{
ARTICLES
}

\section{Search and Rescue: Rebuilding a Test Collection}

\author{
by Peggy S. Cooper and J. Stephanie Weiner
}

\begin{abstract}
Evaluation instruments are a frequent adjunct to the fields of education and psychology. This paper recounts the salvaging of a moribund test collection - how the authors went about rebuilding the Western Oregon State College Library test collection. Generating faculty involvement in the enterprise, creating a database to provide bibliographic control and efficient collection maintenance, and distributing responsibility for the collection between two library departments were key elements of the procedure. Appointment of a separate line-item in the library budget for test acquisitions, rapid completion of the project (less than six months), and development of a test database were the most notable results of this project.
\end{abstract}

\section{BACKGROUND}

Western Oregon State College is a small liberal arts college with an average annual enrollment of 4000 students. Like many institutions thatevolved fromstate teacher's colleges and normal schools, it maintained a curriculum library as an integral part of the teaching resources. Responsibility for the curriculum library had of ten shuttled between the education department and the library.

Although the curriculum library at Western remains a responsibility of the Education Department, the test collection came under the aegis of the library in the fall of 1987 . The collection of 341 standardized tests (unique titles, not including duplicates), was transferred to the library when the Learning Activities Resource Center (LARC) moved from the education building to its current location in the Instructional Technology Center.

The main body of the collection included tests that were received in a random fashion as gifts from education faculty, as well as aminuscule number purchased upon faculty request. No additional tests were added to the collection between 1987 and 1990 , and no manuals or policy statements existed to provide guidance for either circulation procedures or for collection development.

The test collection was moved to the library for several reasons, including space and budgetary limitations. Not only had the collection never been evaluated or inventoried, but many of the tests were either duplicated, outdated, or incomplete. The only bibliographic control of the collection was a list kept at the reference desk arranged by title, author, call number and acronym. Dewey Decimal numbers had been assigned to the tests by staff in the Learning Activities Resource Center (LARC); however, these recordss were never integrated into the library's card catalog.

\section{INTRODUCTION}

In May of 1990, the authors - as collection development librarians for Education and Psychology - were charged with evaluating and upgrading the Western Oregon State College Library's test collection. The Library Director agreed to reserve a sum of $\$ 5000$ from the library's annual materials budget for this purpose. The potential for interdisciplinarity of the collection was explored, courses that might involve the use of tests were identified, and appropriate faculty contacted. With faculty assistance, outdated tests were weeded and new and/or revised tests were acquired. Policies and procedures for test acquisition, processing, and maintenance were developed, and a test database was constructed to assist with processing and reporting information. The time frame - less than six months - of the rebuilding process was extremely important in providing continuing faculty supportby displaying tangible results in a timely manner. Unlike 
many other institutions, where the test collection is underfunded, this collection was given a generous materials allocation for the initial rebuilding process and assurance of an annual line item for test materials (Ginn \& O'Brien, 1984/85). The library was fortunate in having a good collection of test evaluation and review source. Thus the initial funds could be used to jump-start this reclamation project rather than for the purchase of supportive material for the collection. The annual line item in the budget ensured permanent support for the collection (which had not previously enjoyed continuous funding), providing greater fiscal control, and freeing any one discipline from being unduly burdened financially. This approach blended well with the reorganization of budget allocations based on discipline rather than format, which was already under way.

\section{METHODOLOGY}

A review of the literature on test collections in academic libraries provided little guidance for planning or implementing this project. With some notable exceptions, e.g. Robert $\mathbf{M}$. Simmons, Rolland H. McGiverin, Alice S. Clark, David Ginn and Nancy O'Brien, it was found that relatively few articles or monographs have been written on test collections and their maintenance. Therefore, the authorsdecided to begin by a review of the existing collection. A list of the tests in the collection was compiled, including information on incomplete sets and duplicate sets of instruments. Key faculty in education were then identified and contacted to advise on retention or discard of items in the existing collection. Due to space limitations, the decision was made not to retain multiple copies, previous editions, or little-used items.

Exploration of the possible expansion of the education/ psychology focus of the collection to include instruments whose use was taught by faculty in other departments was the next step of the rebuilding process. By reviewing the college catalog (Simmons, 1979), twenty faculty members were identified who might be interested in teaching about tests in the areas of Education, Psychology, Physical Education, Criminal Justice, Sociology, Business, English as a Second Language, Special Education, Clinical Child \& Youth Work, Teaching Research, and Student Development. Those faculty members were subsequently sent (1) a photocopy of the current test holdings list for suggestions for removal or retention, (2) a photocopy of test titles from the subject index of the latest volume (VII) of Test Critiques (Keyser \& Sweetland, 1988), (3) a needs assessment survey (ALA, 1985) to elicit their specific needs for test materials (see Appendix I), and (4) a bibliography of library holdings on the topic of tests and testing.

While waiting for faculty members to respond to the needs assessment survey (approximately $90 \%$ did complete and return surveys), a bibliography was compiled of all books held by the library relating to tests. This list was distributed to the participating faculty. The twenty faculty who planned to use the test collection and expressed interest in it were invited to attend a meeting held to discuss new acquisitions, collecting levels, and collection access (ALA, 1985). Approximately one half of the invited faculty members either attended the meeting themselves or sent department representatives. One of the critical outcomes of this meeting was the decision to order specimen sets when available (Simmons, 1979 and McGiverin, 1990), which enhanced the buying power of the allotted funds. One example is the Cattells' Cultural Fair Intelligence Tests which costs $\$ 38.25$ for the introductory kit and $\$ 7.75$ for the specimen set, a savings of $\$ 30.50$.

Following the meeting, faculty responses to the survey and their recommendations for retention or deletion that were noted on copies of the current holdings list were reviewed. Based on faculty recommendations, approximately $85 \%$ of the tests which were either dated, irrelevant, or incomplete, were discarded from the collection.

A list of items to be purchased was then compiled, including both new titles and later editions of items already in the collection. Test publishers were identified through use of Tests (Sweetland \& Keyser, 1986) and current catalogs with price and availability information were requested, as Simmons (1979) recommends. These catalogs were retained for future use. Prices were added to the list of items requested for purchase, and the list was then evaluated, establishing criteria for purchase and priority of items to be ordered (McGiverin (1990).

Criteria for purchase were as follows:

1) items requested by more than one faculty member in two or more departments;

2) items requested by more than one faculty member in the same department; and

3) items costing less than $\$ 100$.

\section{RESULTS}

\section{Ordering}

An initial set of 95 tests were ordered. A separate budget code was established for the test collection in order to facilitate fund accounting. Orders were generated through the library book vendor's automated ordering system. Many publishers required authorization forms from both teaching faculty and the library (Simmons, 1979) guaranteeing that tests would be used in compliance with the publishers' regulations.

\section{Receiving and Processing}

After initial receipt in technical services, items were deleted from the vendor database. The order slip and item were then routed to one of the authors for verification of receipt of complete order and invoice approval.

Since the tests were not cataloged, it was necessary to provide bibliographic control of the collection. A test collection database, using a dBase III program, was created. The test database contains the following fields: 
title

edition

acronym

price

author

publisher

publication date

requesting faculty

accession number

items in packet

\section{character}

character

character

numeric

character

character

character

character

character

numeric
58

58

10

52

30

30

8

30

6

2 formed:

The database allows the following functions to be per-

1) add new tests;

2) update, edit, scan, and find tests currently in the database;

3) generate labels to be placed on each test envelope or case, labels contain all of the information from the entry fields except price, requesting faculty, and copy number (Ginn \& O’Brien, 1985); and

4) generate alphabetical holdings lists of the test collection by author, title, and/oracronym. (See Appendix II for the test menu and entry options.)

From this database, current lists of tests in the Library's collection were generated, and arranged alphabetically by author, title, and acronym. These lists were placed in looseleaf binders along with the following collateral material:

1) a copy of the test collection circulation policies and procedures;

2) a memo to faculty informing them of procedures they are required to follow to enable their students to utilize the test collection (Appendix III);

3) a faculty approval form (distributed to all relevant faculty) (see Appendix IV);

4) a bibliography of the library's monographic holdings related to tests; and

5) a test purchase request form (see Appendix V).

Binders are located at the Reference Desk and the Circulation Desk in the Library. In addition, binders were sent to all departments utilizing the test collection for ease of access by faculty.

Processing of a large quantity of new materials required assignment of additional personnel to this task. For three months, as the items were received, a student worker was assigned to this project.

Additional supplies were purchased, costing approximately $\$ 250$, and consisting of: two sizes of file folders (1 plain, 1 accordionstyle), property stamp, and labels for file folders, and test materials. Processing included the following tasks:
1) entering the test into the database;

2) generating labels for the folders from the database;

3) counting the number of items in each test packet (to ensure return of all materials when item circulated), and affixing a label with a sequential number to each test item. The total number of items is entered into the database, and displayed on the label generated for the test folder;

4) affixing pockets for circulation cards to each folder;

5) typing test title on each circulation card;

6) inserting a copy of the circulation policies and procedures in each folder (Simmons, 1979 and McGiverin, 1990);

7) affixing a label stating copyright restrictions (McGiverin, 1990);

8) filing folders of tests alphabetically by test title (Simmons, 1979 and ALA, 1985); and

9) placing dummies in the test file for oversize items shelved separately (Simmons, 1979).

\section{Circulation Policies and Procedures}

Due to the sensitive nature of test materials, it was essential to develop a circulation policy that would enable the materials to be used without jeopardizing the agreements made with the publishers. The following policies were established for test collection usage at WOSC Library:

1) Faculty members will supply the Circulation Unit of the Library with class lists for each course that requires use of the test collection (ALA, 1985). For special or individual studies, the supervising faculty member must provide written approval for the individual(s) using test materials.

2) Only those students whose names appear on the class lists will be allowed to use tests and test materials.

3) Current student I. D. is required to check out materials from the collection.

4) Tests are kept on reserve at the circulation desk and are for use in the library only. They may be checked out for two hours with one two-hour renewal if no one else is waiting for the item (Clark, 1982).

5) The contents of the test container must be reviewed with a library staff member when it is returned to the reserve desk. The patron is responsible for the replacement cost of damaged or missing elements. The minimum charge is $\$ 10.00$; the maximum charge is the full replacement cost of the test, which ranges from $\$ 10$ $\$ 500$ (Simmons, 1981).

At the WOSCLibrary, tests are not cataloged, are not a part of either the circulating collection or the reserve collection, and have special circulation requirements. Therefore, separate checkout procedures were established. These procedures emphasize the elements of test security and patron accountability (Simmons, 1981 and ALA, 1985) (see appendix VI). 


\section{Location}

The test collection is housed in two 4-drawer legal size file cabinets located in the staff work area and accessible to the circulation area (Simmons, 1979 and McGiverin, 1990). Oversized material is housed on shelves near the circulation area (ALA, 1985). Dummies placed within the test file drawers enable rapid retrieval of these materials. The circulation personnel are responsible for retrieving and refiling the tests, and this is made easier by having the test files arranged alphabetically by title.

\section{CONCLUSIONS}

Six features emerged that seem atypical according to the supporting literature on test collections:

1) Two bibliographers were equally responsible for all elements of the test collection enterprise.

2) The elapsed time from start to conclusion was comparatively short, unlike many library projects. The total time period was seven months.

3) An in-house database was developed. Plans have been made to modify the database to increase access point to the materials, and to generate administrative reports.

4) The scope of the collection and the faculty involved were unusually multi-disciplinary, drawing on more than the usual Education/Psychology combination, and including disciplines less commonly represented in test collections, such as Physical Education, Criminal Justice, and Sociology.

5) The literature indicates that this may be the only academiclibrary w ith a line-item for tests in its budget. Funds for test purchases are normally taken from money reserved for subject specific purchases as in the area of education. This provided the added and unanticipated benefit of insuring continuous financial support (McGiverin, 1990).

6) Faculty enthusiasm was so great that several members donated items from their personal collections (Simmons, 1979).

The existential approach to rebuilding the test collection had some advantages as well as some disadvantages. The two disadvantages to this free-form method of collection development were 1) a lack of clearly defined procedures for some portions of the acquisition process and 2) fewer access points in the database than might be desired.

On the positive side, by not following the traditional Education/Psychology pattern, the potential clientele was expanded io include additional academic disciplines and departments. The lack of a rigid, preconceived collection development philosophy allowed for an open-ended dialogue with faculty, and resulted in a high level of faculty input and their resultant "ownership" in the collection. This same degree of flexibility allowed for completion of the project in a relatively brief period of time. Guidelines were written that met the needs of the collection, rather than developing a collection that met the pre-established guidelines.

\section{RECOMMENDATIONS}

The recommendations that follow are based on experience gained during this project as well as two common denominators - naiveté and hindsight - and have been incorporated in the procedures for the test collection at Western Oregon State College.

1) Establish a line item in the budget for the test collection; this ensures continuing financial support.

2) Establish written documentation of acquisition and receipt procedures specific to tests with all relevant departments within the library, and complete this step prior to ordering test materials (ALA, 1985).

3) File tests alphabetically by title rather than by subject to minimize training time and filing errors.

4) Share responsibility for the test collection; this distributes the workload more evenly, increases the knowledge base, and adds to the number of personnel available to assist in maintenance (see the earlier comments on staffing patterns).

5) Review materials in the collectionannually and involve both faculty and librarians in the process to ensure a relevant and well-rounded collection.

6) Involve faculty in the selection of materials and provide them with information on the collection, such as lists of holdings and use of statistics.

7) Initiate a test collection database which will aid in processing materials and provide greater bibliographic control.

\section{REFERENCES}

Clark, A. S. (1982). Managing curriculum materials in the academic library. Metuchen, NJ: Scarecrow.

Ginn, D., \& O'Brien, N. (1984/1985). Selected test collections in the United States: A survey of organization. Behavioral \& Social Science Librarian, 4(2/3), 9-20.

American Library Association. (1985). Guide for the development and management of test collections with special emphasis on academic settings. Chicago: Author.

Keyser, D. J., \& Sweetland, R. C. (Eds.). (1988). Test critiques (Vol. 7). Kansas City, MO: Test Corporation of America.

McGiverin, R. H. (1990). Educational and psychological tests in the academic library. Behavioral \& Social Sciences Librarian, 8(3/4), 1-85.

Simmons, R. M. (1979). Organizing and servicing a collection of standardized tests: A manual for librarians. Arlington, VA: Educational Resources Information Center. (ERIC Document Reproduction Service No. ED 180 434)

Simmons, R. M. (1981). Standardized test collection management. Education Libraries, 6(3), 67-70. 
Sweetland, R. C., \& Keyser, D. J. (Eds.). (1986). Tests: $A$ comprehensive reference for assessment in psychology, education, and business. (2nd ed.). Austin, TX: Pro-Ed.

Peggy Cooper Collins, Collection Development/Circulation Services Librarian, Western Oregon State College Library.

J. Stephanie Weiner, Serials/Microforms Librarian, Western Oregon State College Library. 